\title{
PCA-ANN Based Algorithm for the Determination of Asymmetrical Network Failures of Network-Connected Induction Generators
}

\author{
Haydar BAYAR, Umit Kemalettin TERZI, Okan OZGONENEL
}

\begin{abstract}
Presented in this study is a principal component analysis - artificial neural network based hybrid failure determination system that can make failure determination selectively and rapidly in asymmetrical external failures that might occur on the network side of a grid-connected induction generator. By creating asymmetrical external failures in the developed simulation model, analysis of noisy and unbalanced fluctuations that carry effects of positive, negative and zero sequence in currents were realized. The suggested model depends on entering data taken from the simulation into the artificial neural network model as a training data by being simplified with principal component analysis, in phase-phase, phase-ground and two phase-ground failures. The protection model makes correct classification with acceptable errors in case of above stated failures. However, in current fluctuations caused by sudden load changes and operation under an unbalanced load, it may remain insensitive by behaving selectively.
\end{abstract}

Keywords: ANN; faults; induction generator; PCA; protection

\section{INTRODUCTION}

With the developing technology, energy prices are increasing due to the increasing energy needs of countries and energy production that cannot reach this speed. Most of the energy needed in the world is provided from fossilbased sources. Fossil fuels pollute the environment; global warming, decreasing reserves, increasing the dependencies of countries and increasing the demand for energy has led to an increase in renewable and alternative energy field. In this respect, researches are focused on renewable energy sources such as wind energy, hydraulic energy, solar energy, geothermal energy, which do not pollute the nature and environment and renew themselves continuously.

Generators used in wind turbines vary in time in parallel with technological developments. These generators are used to convert the mechanical energy produced by the wind turbine into electrical energy with minimum loss. It is possible to divide the generators used in wind turbines into 3 main groups.

- DC generator

- Synchronous generator

- Asynchronous generator (IG)

Direct current (DC) generators, which are widely used in small powerful systems, are replaced by alternating current generators with the development of technology. These generators can easily convert energy by using power electronics. Synchronous and asynchronous generators are more widely used in wind turbines that operate in parallel with the grid in medium and large power systems.

The asynchronous generators are widely used today in wind and mini hydroelectric power plants that have the highest increase rates in respect to installed power. These generators are especially preferred because of their significant advantages such as simple structures and their control advantages during speed changes in the grid connected to high powered wind turbines. Detailed comparisons of induction generators (IGs) used in the wind plants are made and related to parameters such as their voltage stability with the synchronous generator wind turbine systems, voltage wave shape, temporary state stability and short circuit levels [1].
During the start and network connection processes, soft-starting models and their effects on the system are examined [2]. Fix speed and double-fed IGs are compared in respect to noise effects they create on the network and their responses in case of network failures [3-5]. Specifically, double-fed IGs are preferred in high power turbines, and their behavioral models in sudden voltage fluctuations, parallel connection systems, symmetrical/asymmetrical short circuits and other mechanical and electrical failures become the subject matter of both simulation and experimental studies [6-10]. In stability analysis of IGs, requirement for a real-time mathematical calculation and measurement of rotor speed or its position can be eliminated by controlling voltage rotor speed and excitation current in load changes to regulate them [11]. In the variable speed wind turbines, end voltage can be controlled by the vector control technique [12].

The electro-mechanic failure determination systems in IGs have significant disadvantages as the spectrum of stator current does not contain the components produced by motor failures, nor does it contain distortions in supply voltage, air gap harmonics, in-conduit harmonics and load imbalances. In these machines, failure signals are masked by powerful background noise. The failure diagnosis system also receives temporary and non-stationary distorting effects coming from inside or outside of the motor. More than one failure may occur simultaneously. In case of different failures, establishment of harmonics and their period will change. In order to eliminate such negative situations, artificial intelligence techniques must be used to process the data in the failure determination point more accurately [13-15].

Minimizing the effects of external failures has an important place in designing protection systems because of their asymmetric structures, and because they are not previously experimentally simulated. The priority goal is to determine the location and character of failure as soon as it occurs. The protection system is directly in charge of that process. With data analysis coming from the protection system, failure points are determined and by planning necessary maintenance processes ahead of time, failures can be prevented. Here, all of the factors that may cause 
failure are considered as data [16]. To determine the failures, protection systems must be reliable, fast and selective against temporary events other than failures $[17$, $18]$.

Asymmetric faults in the asynchronous generator which cause imbalance are very dangerous and should be detected in the shortest time. Terminal faults such as phaseto-earth, phase-to-phase, open-circuit and winding short are the most common fault type for IGs and must be detected quickly. In this respect, this paper is the extended version of referenced paper of Authors [17] and analyses the terminal faults rather than internal faults in IGs.

In this study, responses of an IG that has the abovestated features to external failures are examined and a principal component analysis (PCA) -artificial neural network (ANN) based hybrid failure determination algorithm that analyzes these responses is developed. PCA-ANN based hybrid terminal fault detection algorithm for IGs can be seen in Fig. 1 .

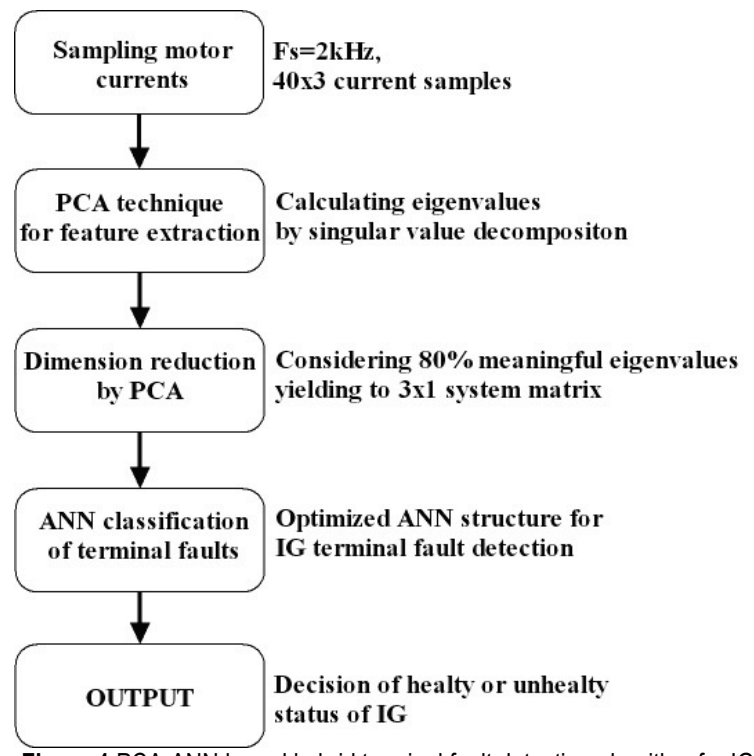

Figure 1 PCA-ANN based hybrid terminal fault detection algorithm for IGs

\section{MATERIAL AND METHOD}

Examining the behavior of a protection system is almost impossible by establishing the real-time short circuits on the network side. Presented in this study is a PCA-ANN based failure estimation model that can make classification in various external failure situations with IG simulation developed for a protection system algorithm that can determine asymmetric network failures.

\subsection{Simulation Model}

The established IG simulation is given in Fig. 2. In this study, phase-ground, phase-phase and phase-phase-ground short circuits are analyzed as external failures. In addition, the behavior system for sudden load changes on the network side is examined.

In the generator model, a three-phase source and load group representing the network, a three-phase error blog used to establish failure situations and the asynchronous machine model are seen. By assigning a negative value to the moment input $(\mathrm{Tm})$ of the developed model, the generator switches to operation mode. This input also indicates the load situation of the machine. Three-phase current information is read on the $m$ outlet of an asynchronous machine model and kept in a variable called "zan". For this registering process, a triggered block is used because the model established in the simulation environment does not operate within a fixed time. The need for simulation to include transient and steady states leads to time intervals in the obtained data and its unconformity is compared to data obtained from other experiments. To prevent this, a pulse generator that produces 2000 pulses per second triggers the data register block and when each triggering signal arrives, existing current signals are registered to the variable in the working environment. The data obtained in this way were prepared to be treated. By using these parameters, each failure situation was established individually and the obtained current data were processed with PCA to calculate residue amplitudes of external failure situations.

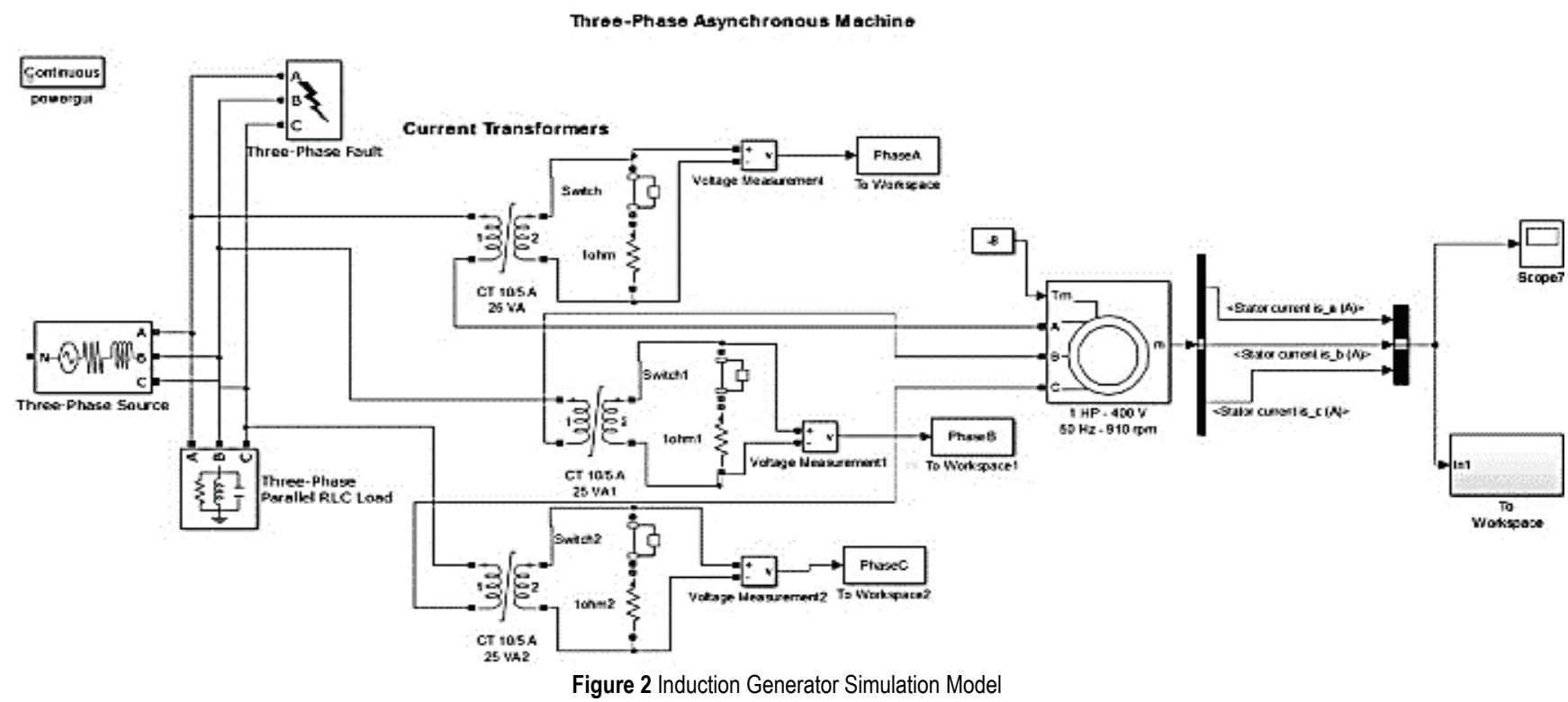




\subsection{Principal Component Analysis}

PCA is a traditional linear feature determination method. PCA depends on the secondary statistical analysis of data, especially on eigenvalue analysis of the covariance matrix. In industrial applications, it is used for failure determination and controlling. Interrelated different measurements included in an operation process and many operation processes that have high noise, are nonlinear and change in time and have to be followed. With PCA applied to failure analysis, nonlinear correlations between different processes can be eliminated and the effect of noise in a failure system can be decreased. For this reason, in condition monitoring of a process or device, PCA is very practical.

In failure analysis with PCA, establishment of a data base consists of multi-variable data related to the general operating conditions of the system and a data monitoring infrastructure constitute the basis of the method.

Hotelling $T^{2}$ and SPE (Squared Prediction Error or $Q$ ) statistical methods set forth general characteristics of data in failure (error) analysis with PCA. By indicating the degree of differences between real time measurement values $(X)$ and basic components $(X p)$, SPE follows the residue subspace. SPE or $Q$ method is defined with the following Eq. (1).

$$
Q=E E^{T}=X^{T}\left(I-P P^{T}\right) X
$$

In this equation, $E$ refers to error matrix, $P$ to eigenvector matrix and $I$ to unit matrix.

The data variances that cannot be explained with basic components are defined with SPE. By taking the secondary total of score vectors, the Hotelling $T^{2}$ statistic used in this study scales the internal variances of PCA model. With this method, it becomes easy to monitor the basic component subspace in real time. Graphics showing the Hotelling $T^{2}$ statistical variances indicate the difference between each sampling point and model in respect to amplitude and direction of variances. The Hotelling $T^{2}$ approach for $X$ data matrix is expressed as:

$$
T^{2}=X P \lambda^{-1} P^{T} X^{T}
$$

Here, $T$ refers to stock vector matrix obtained from basic components and $\lambda$ refers to diagonal matrix consisting of eigenvalues. As it is seen, $T^{2}$ has a scalar magnitude that is equal to the total of numerous variances. For this reason, it gives opportunity to follow multivariable tracing processes through one variable. $T^{2}$ statistic method expresses the changes in multi-variable operation processes in terms of fluctuation in the basic component vector amplitudes in the PCA model $[19,20]$.

\subsection{ANN Model}

In the proposed study, PCA is used for extracting feature vectors by reducing the dimensions and ANN is used for classification algorithm. The PCA is said to be working as current signature analysis of the IG under analysis. The current samples (originally $40 \times 3$ matrix form) are preprocessed by PCA to dimension reduction and related eigenvectors are then supplied to ANN input for decision making i.e. the faulted and normal state residue data with PCA output obtained as a result of the experiments were used to train the ANN that was used in the failure determination phase. The network is created by the Matlab Neural Network Fitting Tool and is a feedforward system and consists of three layers as input, hidden and output layers and contains a sigmoid transfer function in the hidden layer and a linear function in the output layer. There are 12 neurons and the best performance is achieved by choosing that amount of neurons in the hidden layer and there is 1 neuron in the outlet layer as given in Fig. 3.

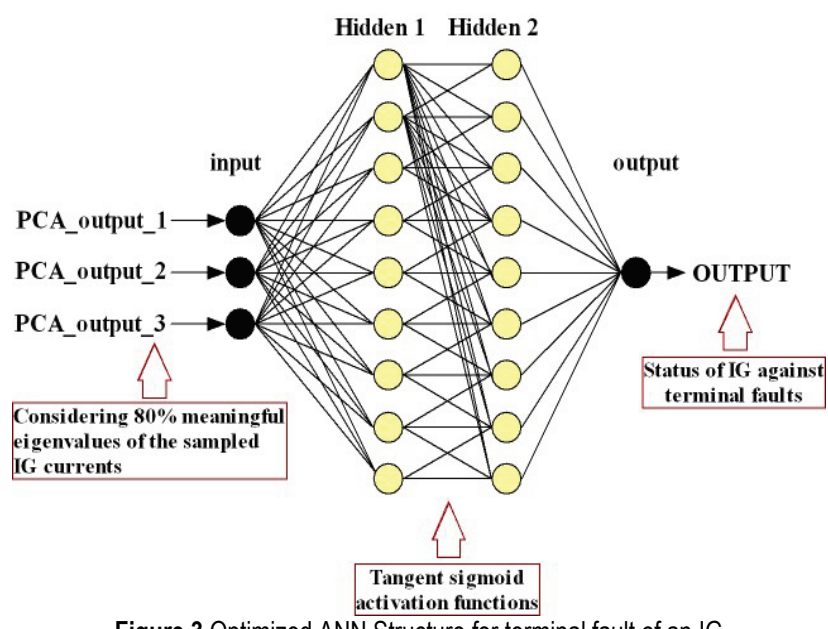

Figure 3 Optimized ANN Structure for terminal fault of an IG

The number of neurons and the type of activation neurons in the hidden layer are simply selected according to the training performance to achieve the maximum testing performance. Momentum and learning rate are chosen as 'auto' which means attempting to move to the global minimum rather than local minimum. As a training method, Levenberg-Marquart is selected among the tested training algorithms (due to its presenting best performance).

The sampling frequency is chosen as $2000 \mathrm{~Hz}$ that corresponds to 40 samples per period for computer simulations. This means that the input data are the form of 40x3 matrix type for all phases. Since sliding-window is used for data processing, the ANN input always takes 40 samples per sampling period. The sampling time $0,5 \mathrm{~ms}$ is chosen and seen adequate to discriminate normal and faulty working conditions. For testing procedure, similarly $40 \times 3$ matrix is used and a decision between the normal and faulty operating conditions is made. The performance results of ANN are given in Table. As seen in Table, maximum deviation between the target and output value for all working conditions is around $1 \%$ which means the proposed protection algorithm is able to discriminate the faulty conditions.

The training step has many working conditions from the smallest one i.e. $10 \%$ to the largest one i.e. $120 \%$ to refrain from the unexpected outputs (especially wrong decisions) by ANN. Along with the several loading conditions, healthy (rated) working conditions are also taken into account to improve ANN performance. By the way, for training procedure the suggested ANN has been run several times to achieve the best training performance. Once the desired performance (greater than 90\%) is 
obtained, the testing data are supplied the input nodes of ANN.

Similar network types including adaptive neuro-fuzzy inference system (ANFIS), generalized regression neural network (GRNN) and multi-layer perceptron (MLP) can be found in literature [21-25].

The proposed network type given in Fig. 3 is able to discriminate the faulty and healthy conditions of the induction generator under testing.

\section{$3 \quad$ RESULTS AND DISCUSSION}

For the $0,3 \mathrm{~s}$ period phase-ground, phase-phase and phase-phase-ground short circuits created at the outlets of the generator, the phase currents and changes of residue vectors calculated as a result of PCA were examined. The phase-ground failure was simulated by contacting one of the phases of the grid-connected generator to ground.

Fig. 4-a shows the effect of a phase-ground short circuit established between $0,1-0,4$ seconds on the generator current. Though the failure is removed in $0,4 \mathrm{~s}$, it is seen that fluctuations in the current continue. It is observed that generator currents become balanced approximately $0,2 \mathrm{~s}$ later. As seen in Fig. 4-b, the effect of imbalance that occurs when the short circuit situation is eliminated on the residue amplitudes is very low.
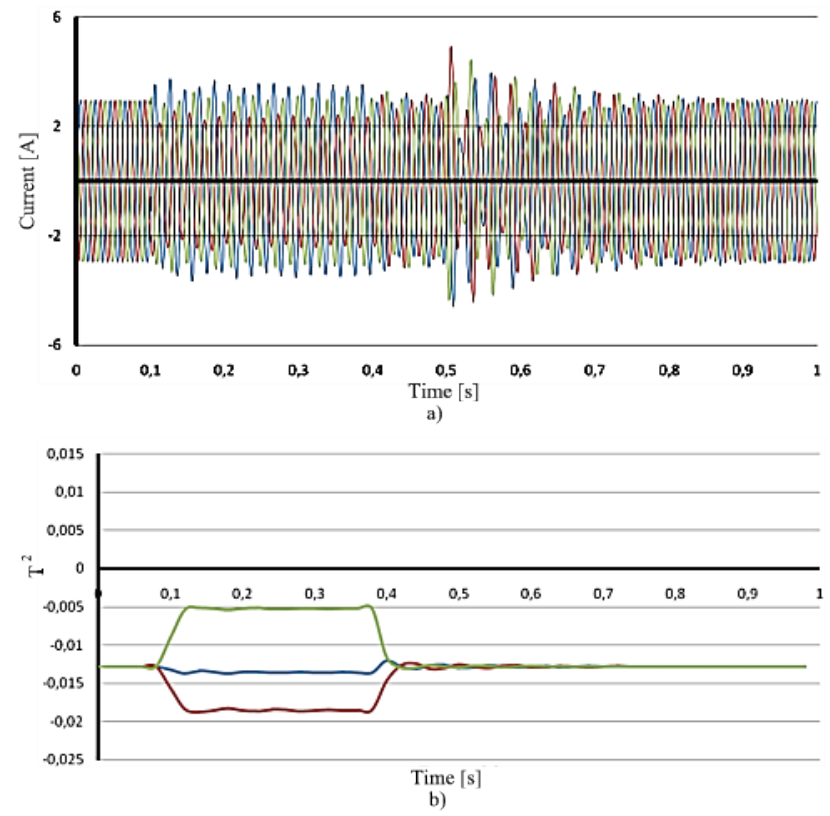

Figure 4 Phase-ground failure: a) phase currents and b) PCA residues $\left(T^{2}\right)$

Fig. 5a shows that currents in the phase-phase short circuit rise 7 times of nominal value. With elimination of failure at the end of $0,4 \mathrm{~s}$, reducing generator currents to nominal values takes about $0,3 \mathrm{~s}$. During the period when failure begins and system current becomes balanced, sudden changes are observed in the residue amplitudes. The same condition occurs as soon as the failure is eliminated. To prevent the effects of these sudden changes on system outputs, the balanced residue amplitudes of failure situation were used in training of the suggested protection system (between 0,2-0,35 seconds) (Fig. 5b).
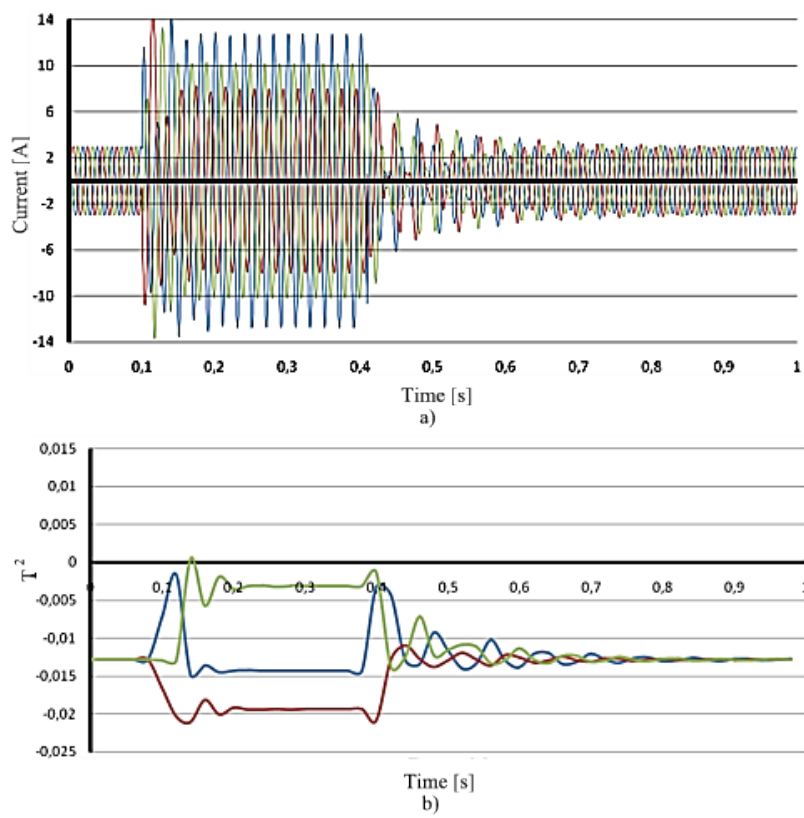

Figure 5 Phase-Phase failure: a) phase currents, b) PCA residues $\left(T^{2}\right)$

The generator current change caused by the phasephase-ground short circuit on the side of the network is given in Fig. 6a. It is determined that failure currents reach levels that are 7-8 times of nominal value. The imbalance in phase currents is the basic characteristic of asymmetrical failures and can be clearly observed here. This imbalance and the forcing characteristic appear in variance graphics of the residue vectors (Fig. 6b). Specifically, sudden amplitude changes in the moment when failure begins have high values.
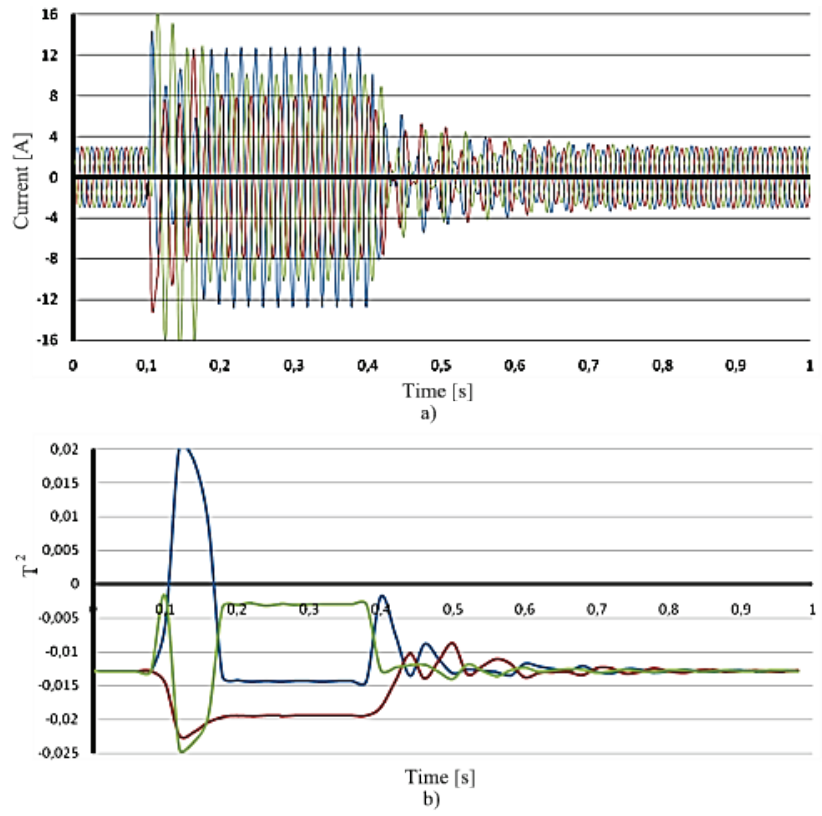

Figure 6 Phase-Phase-Ground failure: a) phase currents, b) PCA residues $\left(T^{2}\right)$

The steady state operation data of IG, for which responses in the failure situations were examined above, were also taken. The steady state defines ideal conditions that do not contain any failure and the generator undertakes nominal load. These data were also taken in a real time operation moment and used in training of ANN model. The elements of the residue matrix, demonstrating a selective 
character and calculated as a result of PCA, were given as input data to ANN. By taking the mean of neural network outputs given in Fig. 7, their proximities to target output values determined by training data for each failure were analyzed.
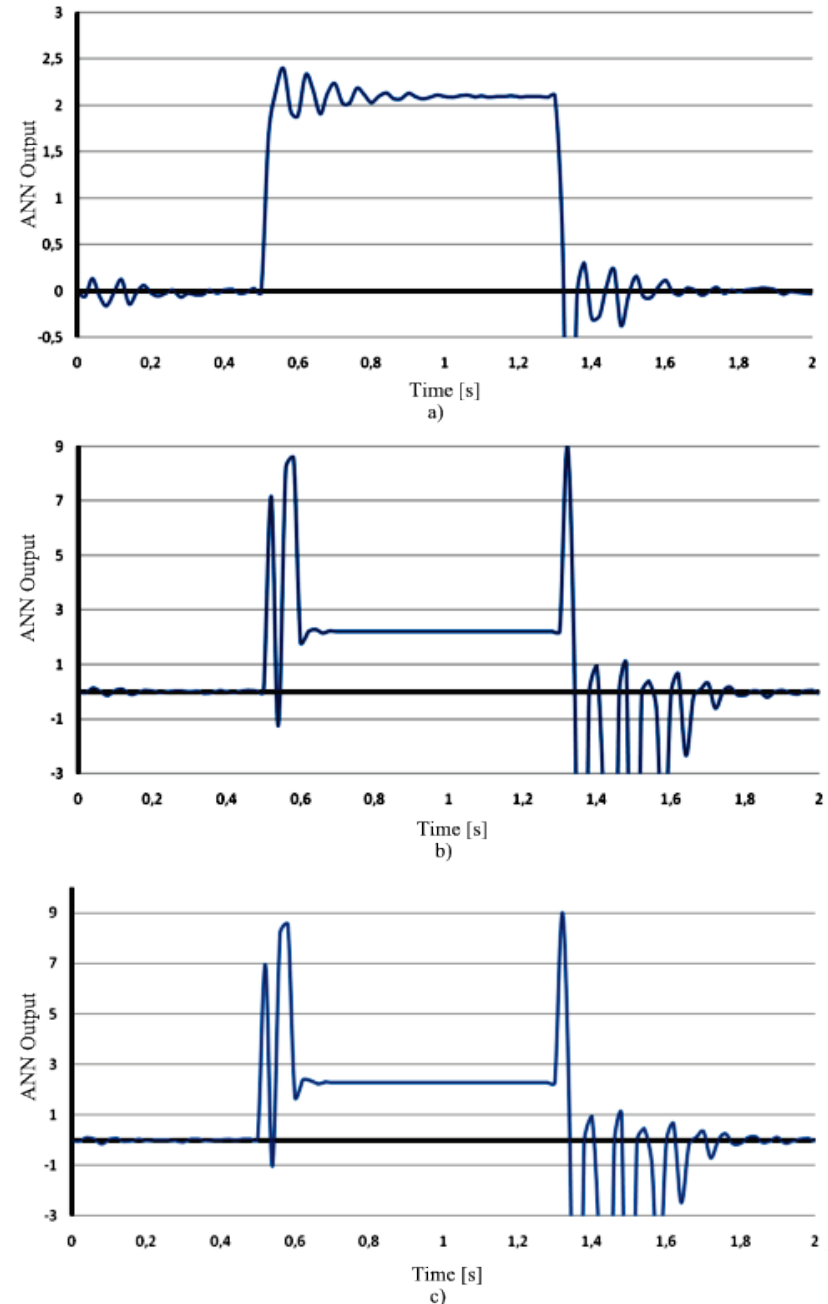

Figure 7 ANN output for: a) phase-ground, b) phase-phase, c) phase-phaseground failures

As seen in Tab. 1, the suggested protection model can make a failure definition with small errors. For the phase to phase fault study the target value is 2,2 but the ANN output produces 2,2221. For the 2 phase - ground fault the target value is 2,3 and the ANN output produces 2,2816. Although the graphical pattern looks similar, the ANN output can discriminate these faults. The biggest error rate (1\%) occurred in the phase-phase short circuit.

Table 1 System outputs corresponding to the failure situations

\begin{tabular}{|l|c|c|c|}
\hline \multicolumn{1}{|c|}{ Failure type } & Target value & $\begin{array}{c}\text { Avg. output } \\
\text { value }\end{array}$ & Deviation (\%) \\
\hline Steady-state & 0,000 & 0,000 & 0,000 \\
\hline Phase-Ground & 2,100 & 2,095 & 0,252 \\
\hline Phase-Phase & 2,200 & 2,222 & $-1,005$ \\
\hline Phase-Phase-Ground & 2,300 & 2,282 & 0,800 \\
\hline
\end{tabular}

One of the reliability features of protection systems is that load changes that occur on the system are not recognized as failure. A selective protection system must be sensitive enough to determine a failure even in conditions that establish current fluctuations under nominal current. Besides, in some situations, it must be insensitive to movements during the routine load startup/cut-out processes that cause current elevations more than many failure situations at the moment of switching. The protection model suggested in this work was tested for the sudden load change by using the online and simulation data.

On the simulation model, a sudden increase of the network load 2 times of the normal load with 0,5 seconds, and returning of the system to normal within 1,2 seconds were artificially simulated.
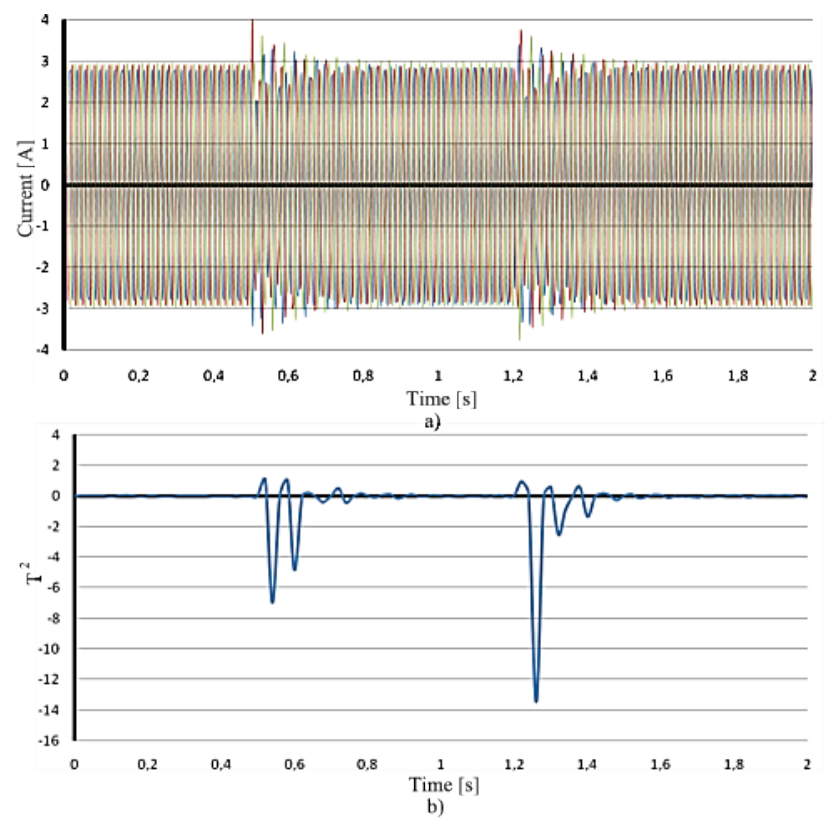

Figure 8 a) Phase currents, b) ANN output changing for sudden load fluctuations

Fluctuations in the current data against this sudden change were reflected as one-period negative and positive changes at the system output (Fig. 8a). As seen in Fig. 8b, though ANN model produces high value strokes during the moments when load start-up/cut-out, the output mean is much lower than the failure values given in Tab. 1 and close to zero, which is accepted as firm value.

\section{CONCLUSIONS}

Protection systems are one of the main sub-systems of modern energy management organizations. Studies related to increasing the effectiveness of such systems require using artificial intelligence techniques and intelligent electronic devices together. These systems try to establish optimal balance conditions between two parameters selectivity and speed - that affect each other the most in protection systems. The selectivity concept refers to the protection system that determines the failure region and range correctly and remains insensitive to network fluctuations not caused by failure. The speed is determined with the cut-out process of the failed network part in the shortest time and in the most reliable manner following determination of failure.

This study suggests a model that simulates the effects of asymmetric external failures that are almost impossible to establish in a laboratory environment or in the field. The failure data obtained through this model were entered into the PCA-ANN hybrid algorithm together with the steady 
state operation data. The model trained for firm operations and faulty conditions may determine the kind of failure occurred in the established failure situations with very small deviations such as $0,25 \%$ for phase-ground failure, $1 \%$ for phase- phase failure and $0,8 \%$ for phase-phaseground failure. As it can be figured out from these values, the accuracy of the proposed method is quite high.

The developed model also demonstrates selectivity in current fluctuations that occur during routine switching processes in which a good protection system is required to remain insensitive. In sudden load changes that occurred on the side of network, ANN did not make a failure definition.

The developed PCA-ANN based hybrid protection algorithm is advantageous because of its simple and lowcost structure. Its sensitivity prevents development of asymmetric short circuits that are accepted as external failures in the generator protection systems by recognizing them rapidly. In this way, it can increase the reliability coefficient of the protection system and its selectivity feature.

\section{REFERENCES}

[1] Freitas, W., Vieira, J. C., Morelato, A., Da Silva, L. C., Da Costa, V. F., \& Lemos, F. A. (2006). Comparative analysis between synchronous and induction machines for distributed generation applications. IEEE Transactions on Power Systems, 21(1), 301-311. https://doi.org/10.1109/TPWRS.2005.860931

[2] Quinonez-Varela, G. \& Cruden, A. (2008). Modelling and validation of a squirrel cage induction generator wind turbine during connection to the local grid. IET Generation, Transmission \& Distribution, 2(2), 301-309. https://doi.org/10.1049/iet-gtd:20060180

[3] Holdsworth, L., Wu, X., Ekanayake, J. B., \& Jenkins, N. (2003). Comparison of fixed speed and doubly-fed induction wind turbines during power system disturbances. IEE Proceedings Generation, Transmission and Distribution, 150(3), 343-352. https://doi.org/10.1049/ip-gtd:20030251

[4] El-Sattar, A., Saad, N., \& El-Dein, M. S. (2008). Dynamic response of doubly fed induction generator variable speed wind turbine under fault. Electric Power Systems Research, 78(7), 1240-1246. https://doi.org/10.1016/j.epsr.2007.10.005

[5] Boutsika, T. N., \& Papathanassiou, S. A. (2008). Shortcircuit calculations in networks with distributed generation. Electric Power Systems Research, 78(7), 1181-1191. https://doi.org/10.1016/j.epsr.2007.10.003

[6] Abad, G., Rodriguez, M. A., Iwanski, G., \& Poza, J. (2010). Direct power control of doubly-fed-induction-generatorbased wind turbines under unbalanced grid voltage. IEEE Transactions on Power Electronics, 25(2), 442-452. https://doi.org/10.1109/TPEL.2009.2027438

[7] López, J., Gubía, E., Olea, E., Ruiz, J., \& Marroyo, L. (2009). Ride through of wind turbines with doubly fed induction generator under symmetrical voltage dips. IEEE Trans. Industrial Electronics, 56(10), 4246-4254. https://doi.org/10.1109/TIE.2009.2028447

[8] Flannery, P. S., \& Venkataramanan, G. (2008). A fault tolerant doubly fed induction generator wind turbine using a parallel grid side rectifier and series grid side converter. IEEE Transactions on Power Electronics, 23(3), 1126-1135. https://doi.org/10.1109/TPEL.2008.921179

[9] Chen, S. Z., Cheung, N. C., Wong, K. C., \& Wu, J. (2009). Grid synchronization of doubly-fed induction generator using integral variable structure control. IEEE Transactions on Energy Conversion, 24(4), 875-883. https://doi.org/10.1109/TEC.2009.2025316

[10] Xiang, D., Ran, L., Tavner, P. J., \& Yang, S. (2006). Control of a doubly fed induction generator in a wind turbine during grid fault ride-through. IEEE Transactions on Energy Conversion, 21(3), 652-662. https://doi.org/10.1109/TEC.2006.875783

[11] Wekhande, S. \& Agarwal, V. (2001). A new variable speed constant voltage controller for self-excited induction generator. Electric Power Systems Research, 59(3), 157-164. https://doi.org/10.1016/S0378-7796(01)00157-2

[12] Idjdarene, K., Rekioua, D., Rekioua, T., \& Tounzi, A. (2008). Vector control of autonomous induction generator taking saturation effect into account. Energy Conversion and Management, 49(10), 2609-2617. https://doi.org/10.1016/j.enconman.2008.05.014

[13] Ghate, V. N. \& Dudul, S. V. (2010). Optimal MLP neural network classifier for fault detection of three phase induction motor. Expert Systems with Applications, 37(4), 3468-3481. https://doi.org/10.1016/j.eswa.2009.10.041

[14] He, Y.-G., Tan, Y.-H., \& Sun, Y.-C. (2004). Wavelet neural network approach for fault diagnosis of analogue circuits. IEE Proceedings-Circuits, Devices and Systems, 151(4), 379-384. https://doi.org/10.1049/ip-cds:20040495

[15] Lee, S.-H., Kim, S., Kim, J. M., Choi, C., Kim, J., Lee, S., \& Oh, Y. (2005). Extraction of induction motor fault characteristics in frequency domain and fuzzy entropy. Paper presented at the Electric Machines and Drives, 2005 IEEE International Conference on.

[16] Uyar, M. (2012). ST and LSSVR-based the fault location algorithm for the series compensated power transmission lines. Energy Educ. Sci. Technol. Part A: Energy Sci. Res., 30(1), 75-88

[17] Bayar, H. \& Terzi, U. K. (2016). Grid-connected induction generator interturn fault analysis using a PCA-ANN-based algorithm. Turkish Journal of Electrical Engineering \& Computer Sciences, 24(3), 1340-1350. https://doi.org/10.3906/elk-1312-145

[18] Rushton, J. \& Mewes, K. G. M. (1995). Protection of generators, transformers, generator-transformer units and and transformer feeders. Power System Protection: Application, 3(1). https://doi.org/10.1049/PBPO905H_ch12

[19] Garcia-Alvarez, D. (2009). Fault detection using principal component analysis (PCA) in a wastewater treatment plant (WWTP). The Proceedings of the International Student's Scientific Conference, 55-60.

[20] Li, D., Zhang, Z., \& Wang, H. (2010). Fault detection and diagnosis in activated effluent disposal process based on PCA. The Information and Automation (ICIA), 2010 IEEE International Conference on. https://doi.org/10.1109/ICINFA.2010.5512366

[21] Kurnaz, Ç., Engiz, B. K., \& Esenalp, M. (2017). A novel throughput mapping method for DC-HSDPA systems based on ANN. Neural Computing and Applications, 28(2), 265274. https://doi.org/10.1007/s00521-015-2054-1

[22] Engiz, B. K., Kurnaz, Ç., \& Kayhan, G. (2012). Performance evaluation of aNN based channel interpolation for oFDM system. The Innovations in Intelligent Systems and Applications (INISTA), 2012 International Symposium on. https://doi.org/10.1109/INISTA.2012.6246975

[23] Ozgonenel, O. \& Karagol, S. (2014). Transformer differential protection using wavelet transform. Electric Power Systems Research, 114, 60-67. https://doi.org/10.1016/j.epsr.2014.04.008

[24] Ozgonenel, O. \& Yalcin, T. (2011). A complete motor protection algorithm based on PCA and ANN: a real time study. Turkish Journal of Electrical Engineering \& Computer Sciences, 19(3), 317-334. 
[25] Ozgonenel, O., Kilic, E., Khan, M. A., \& Rahman, M. A. (2008). A new method for fault detection and identification of incipient faults in power transformers. Electric Power Components and Systems, 36(11), 1226-1244.

https://doi.org/10.1080/15325000802084737

\section{Contact information:}

Haydar BAYAR, Assistant Prof. Dr.

Department of Marine Engineering Operations,

Faculty of Naval Architecture and Maritime, Yildiz Technical University,

Istanbul, Turkey

hbayar@yildiz.edu.tr

\section{Umit K. TERZI, Associate Prof. Dr.}

(Corresponding author)

Department of Electrical \& Electronics Engineering,

Faculty of Technology, Marmara University,

34722, Istanbul, Turkey

terzi@marmara.edu.tr

Okan OZGONENEL, Prof. Dr.

Department of Electrical \& Electronics,

Faculty of Engineering, Ondokuz Mayis University,

Samsun, Turkey

okanoz@omu.edu.tr 